\title{
Analisa Kepuasan Sistem Informasi Akademik Mahasiswa Menggunakan E-Servqual
}

\author{
Annisa Putri Rahayu ${ }^{(1)}$, Heribertus Budi Santoso ${ }^{(2)}$, Sri Rahayuningsih ${ }^{(3)}$ \\ ${ }^{(1)}$ Program Studi Teknik Industri, Fakultas Teknik, Universitas Kadiri \\ Email : annisa11.putri@gmail.com ${ }^{(1)}$
}

\begin{abstract}
Abstrak
Sistem Informasi Akademik Mahasiswa mempunyai peranan penting dalam menyediakan informasi kepada mahasiswa dalam bentuk layanan elektronik. Di Universitas Kadiri Sistem Informasi Akademik nya masih tergolong muda dan tak lepas dari permasalahan, oleh karenanya perlu diidentifikasi atribut-atribut apasajakah yang dinilai masih perlu dibenahi dan ditingkatkan lagi kualitas pelayanannya. Maka dari itu penelitian ini bertujuan guna mengetahui tingkat kepuasan pengguna serta atribut EServqual apasajakah yang nilai kepuasannya rendah. Dimensi E-Servqual digunakan untuk mengetahui atribut-atribut yang nantinya akan diteliti dan ditanyakan kepada responden. Dimana responden yang diteliti ialah mahasiswa semester 4 dan 6 Universitas Kadiri sejumlah 96 mahasiswa, jumlah responden didapat dari perhitungan menggunakan pendekatan Slovin. Hasil dari penyebaran kuisioner akan di uji reliabilitas dan validitas, yang selanjutnya akan diolah dengan metode IPA (Importance Performance Matrix). Hasil penelitian dari jumlah kuisioner 96 responden didapatkan hasil 55 mahasiswa laki-laki dan 41 mahasiswa perempuan, dan mahasiswa semester 6 yaitu dengan jumlah mahasiswa 60 mahasiswa dan 39 lainnya mahasiswa semester 4 yaitu sejumlah 36 mahasiswa. Hasil analisa penelitian menunjukkan bahwa kepuasan pengguna SIAKAD masih rendah dikarenakan ratarata persepsi $(3,13)$ lebih kecil dibandingkan dengan rata-rata ekspektasi $(3,59)$. Selanjutnya atribut yang menempati kuadran I setalah dianalisis menggunakan metode IPA ialah dimensi fulfilment, responsiveness, reliability, efficiency, dan compentation..
\end{abstract}

Kata Kunci: Dimensi E-Servqual, metode Important Performance Matrix, Sistem Informasi Akademik

\begin{abstract}
The student academic information system plays an important role in providing information to students in the form of electronic services. At the Kadiri University The academic information system is still young and not separated from the problem, therefore it is necessary to identify the attributes of the Apasajakah which is assessed still need to be addressed and improved quality of service. Therefore, this research aims to determine the level of user satisfaction as well as attribute E-Servqual Apasajakah whose satisfaction value is low. The E-Servqual dimension is used to identify the attributes that are later examined and asked by respondents. Where the respondents studied were students of semester 4 and 6 of the Kadiri University for 96 students, the number of respondents gained from calculations using Slovin's approach. The result of the distribution of the questionnaire will be in the reliability and validity test, which will then be processed by the method of IPA (Importance Performance Matrix). The results of the research of the number of questionnaire 96 respondents obtained the results of 55 male students and 41 female students, and the 6th semester students with the number of students of 60 students and other 39 students of semester 4 are a number of 36 students. The results of research analysis showed that the satisfaction of SIAKAD users is still
\end{abstract}


low because the average perception (3.13) is less than the average expectation (3.59). Furthermore, the attribute that occupies the Iquadrant is analyzed using the IPA method is the dimensions of fulfilment, responsiveness, reliability, efficiency, and compentation.

Keyword : E-Servqual dimension, Important Performance Matrix method, Academic information System

\section{Pendahuluan}

Dewasa ini semakin banyak organisasi yang menerapkan teknologi informasi yang baru, organisasi mulai untuk meningkatkan kualitas layanan agar tetap kompetitif, karena kualitas layanan terbukti memberikan kepuasan dan kesetiaan pelanggan terhadap organisasi. Organisasi dituntut beradaptasi dengan lingkungan yang semakin tidak menentu. Untuk mencapai kesuksesan dan bertahan pada era persaingan saat ini, perlunya adanya peningkatan kualitas layanan di berbagai aspek, baik produk barang maupun jasa dengan dengan senantiasa melakukan inovasi [1]. Pada implementasinya sistem kepuasaan pengguna (User Satisfaction) merupakan salah satu ukuran kesuksesan [2]. Jika pengguna tidak puas dengan suatu sistem informasi, maka sulit untuk mempertimbangkan keberhasilan suatu sistem informasi. Hal itu tidak hanya berlaku untuk organisasi jasa yang berorentasi profit, tetapi juga pada organisasi jasa seperti perguruan tinggi ini [3].

Implementasi sistem informasi dalam lingkungan perguruantinggi digunakan untuk pengolahan data akademik yang sering dikenal dengan sebutan Sistem Informasi Akademik (SIAKAD). Kegagalan implementasi sistem informasi dan fenomena tambal sulam aplikasi sistem informasi ternyata juga dapat terjadi dalam SIAKAD, hal ini dapat dibuktikan dengan masih adanya perguruan tinggi yang telah melakukan pengembangan dan implementtasi SIAKAD lebih dari satu dekade lamanya, namun hasilnya belum memuaskan hingga saat ini [1]. Tak hanya terhadap perguruan tinggi, adanya Sistem Informasi Akademik atau SIAKAD ini nantinya akan berdampak besar terhadap mahasiswa, dengan alasan sudah waktunya teknologi informasi diterapkan di perguruan tinggi [4], [5], .

Selain itu juga terdapat alasan praktis karena dapat dilakukan dimana saja dan tidak harus menunggu dosen untuk administrasi akademik. Sebagian kecil menyatakan kurang senang dengan alasan mereka masih mengalami kesulitan untuk mengakses dikarenakan jumlah komputer dan konektivitas internet yang masih terbatas.

Kurangnya fungsi sistem yang diterapkan terbukti menjadi salah satu faktor penyebab gagalnya implementasi sistem informasi pendidikan tinggi di Australia. Hal ini mendorong adanya suatu kebutuhan penting untuk melakukan evaluasi secara obyektif tentang keberhasilan atau kegagalan sistem yang berguna dalam mendukung pembuatan keputusan yang tepat. Universitas Kadiri merupakan salah satu perguruan tinggi yang telah memanfaatkan sistem informasi dalam bidang akademik, pemanfaatan ini terlihat dengan adanya pengembangan Sistem Informasi Akademik berbasis web yaitu SIAKAD Mahasiswa. Berdasarkan informasi yang diberikan oleh Kepala Bagian Pelayanan dan Sistem Informasi (BAPSI) Universitas Kadiri, Sistem Informasi Akademik atau SIAKAD Mahasiswa ini telah dikembangkan sejak 2016 lalu. Usia SIAKAD Mahasiswa yang masih tergolong muda ini tak lepas dari permasalahan, seperti masih adanya error sistem ketika memprogram KRS, nilai pada KHS yang tidak sesuai, dan lain sebagainya.

Kurangnya perhatian khusus terhadap Sistem Informasi Akademik Mahasiswa oleh perguruan tinggi ini akan semakin menghambat proses akademik mahasiswa, karena mahasiswalah yang merasakan langsung bagaimana keadaan sistem informasi yang diberikan oleh pihak perguruan tinggi, khususnya Universitas Kadiri. Dari hal diatas maka penelitian ini bertujuan guna mengetahui tingkat kepuasan mahasiwa dan juga dimensi apa yang mempengaruhi tingkat kepuasan Sistem Informasi Akademik menggunakan E-Servqual [6], [7], [8] E-Servqual sendiri ialah suatu konsep kualitas layanan internet atau dapat juga disebut eKualitas pelayanan, dapat didefinisikan sebagai evaluasi keseluruhan konsumen dan penilaian dari keunggulan dan kualitas e-penawaran layanan di pasar virtual [9]. Diharapkan penelitian ini mampu memberikan informasi baik kepada pihak Universitas Kadiri agar mampu memenuhi keinginan mahasiswa sehingga kualitas layanan Sistem Informasi Akademik 
Mahasiswa Universitas Kadiri dapat ditingkatkan. Kontribusi dari penelitian ini juga bisa menambah teori ilmu pengetahuan khususnya dalam rekayasa kualitas jasa dengan implementasi di dunia akademik secara langsung.

\section{Metode Penelitian}

\subsection{Variabel dalam Penelitian}

Variabel yang digunakan dalam penelitian ini adalah E-Servqual. Definisi operasional penelitian ini dapat dilihat pada table berikut ini :

Tabel 1 Variabel penelitian

\begin{tabular}{|l|l|l|l|}
\hline ariabel & i & or & \\
\hline Dimensi E-Servqual & ice Quality & 1. Eficiency & ikert \\
& didefinisikan sebagai & 2. Reliability & \\
& perluasan dari & 3. Fulfillment & \\
& kemampuan suatu & 4. Privacy & \\
& situs untuk & 5. Responsiveness & \\
& memfasilitasi & 6. Compentation & \\
& kegiatan belanja, & 7. Contact & \\
& pembelian, dan & 8. Usability & \\
& distribusi secara & 9. Aestetic & \\
& efektif dan efisien & & \\
& [10] & & \\
\hline
\end{tabular}

(Sumber : Data Hasil Penelitian)

\subsection{Sumber Data dan Metode Pengumpulan Data}

Penelitian ini merupakan sebuah penelitian kuantitatif atau dapat diartikan sebagai sebuah metode yang lebih menekankan pada aspek pengukuran secara obyektif terhadap fenomena sosial. Pada umumnya teknik pengumpulan data yang dipergunakan dalam penelitian kuantitatif ialah kuisioner, yaitu dengan memberikan pertanyaan tertulis pada responden untuk dijawab, yang kemudian jawaban tersebut nantinya akan diolah dan menghasilkan sebuah kesimpulan [11], [12]..

\subsection{Teknik Pengumpulan Data}

Untuk mendapatkan data yang lengkap dan akurat serta dapat dipertanggungjawabkan kebenaran ilmiahnya, penulis menggunakan teknik pengumpulan data ialah Kuesioner, Studi Pustaka dan Interview (Wawancara) [13], [14].

\subsection{Populasi dan Sampel}

Populasi adalah wilayah generalisasi yang terdiri atas: obyek/subyek yang mempunyai kualitas dan karakteristik tertentu yang ditetapkan oleh peneliti untuk dipelajari dan kemudian ditarik kesimpulannya. Sampel adalah bagian atau jumlah dan karakteritik yang dimiliki oleh populasi tersebut. Teknik pengambilan sampel dalam penelitian ini dilakukan mengacu pada pendekatan Slovin, rumus slovin adalah sebuah rumus atau formula untuk menghitung jumlah sampel minimal apabila perilaku dari sebuah populasi tidak diketahui secara pasti, pedekatan ini dinyatakan dengan rumus sebagai berikut [15] :

Keterangan :

$$
n=\frac{N}{1+N\left(e^{2}\right)}
$$

$\mathrm{n}:$ Besar sampel

$\mathrm{N}$ : Besar Populasi

e : kelonggaran ketidaktelitian kesalahan sampel yang masih bisa ditolerir 
Dengan menggunakan rumus dari Slovin untukmenentukan besarnya sampel dalam penelitian ini. Dengan N sebesar 2738, dan dengan tingkat kelonggaran ketidaktelitian sampel yang masih dapat ditolelir atau e sebesar $10 \%$ maka menghasilkan besar sampel 96.

\subsection{Tahap Penelitian}

Tahapan penelitian merupakan gambaran mengenai tahapan persiapan dan pelaksanaan yang dilakukan dalam penelitian [16]. Langkah-langkah penelitian perlu disusun secara baik untuk mempermudah penyusunan laporan penelitian. Langkah tersebut antara lain :

1. Identifikasi masalah dan tujuan penelitian Menentukan masalah apa yang terjadi pada obyek yang akan diteliti untuk dicari solusi atau pemecahan masalahnya. Selanjutnya menentukan apa yang menjadi tujuan dari penelitian yang akan dilakukan.

2. Menentukan Populasi dan Sampel Menentukan banyaknya jumlah populasi dan menghitung jumlah sampel untuk memudahkan penelitian.

3. Penyebaran Kuesioner Mencari informasi yang lengkap mengenai suatu masalah dan responden.

4. Pengumpulan Data Mengumpulkan data yang dibutuhkan dan diambil dari obyek.

5. Pengujian Data

a. Uji Validitas Jika data valid maka dilanjukan ke uji reliabilitas Jika data tidak valid maka kembali pada penyebaran kuesioner.

b. Uji Reliabilitas Jika data reliabel maka dilanjutkan ketahap berikutnya Jika data tidak reliabel maka kembali pada penyebaran kuesioner.

6. Analisis Menganalisis hasil dari pengolahan data dan hasil identifikasi atribut.

7. Kesimpulan dan Saran Membuat kesimpulan dan saran hasil identifikasi atribut.

\section{Hasil dan Pembahasan}

\subsection{Responden}

Pada penelitian ini penulis menggunakan responden yang berjumlah 96 orang yang di ambil dari sampel yang ada dengan cara menggunakan teknik sampel acak (Random sampling) dengan batasan kesalahan sebesar 10\%. Hasil penelitian terlihat bahwa responden 55 laki-laki dan 41 perempuan dengan responden semester yaitu 60 mahasiswa dari semester 4 dan 36 mahasiswa dari semester 6.

\subsection{Pengolahan Data}

Pengolahaan data terdiri dari beberapa tahapan. Tahapan tersebut adalah uji validitas dan reliabilitas pertanyaan, analisa dan identifikasi atribut yang bernilai rendah dengan analisis diagram kartesius.

a. Uji Validitas Untuk mengetahui sejauh mana ketepatan suatu alat ukur dalam melakukan pengkuran atas apa yang diukur. Uji Signifikasi dilakukan dengan membandingkan nilai $\mathbf{R}_{\mathrm{Hitung}}$ dan $\mathrm{R}_{\text {Tabel }}$ untuk degree of freedom $(\mathrm{df})=\mathrm{n}-2$, dalam hal ini adalah jumlah sampel. Jumlah Sampel pada penelitian ini adalah $(\mathrm{n})=96$ dan besarnya df dapat dihitung $96-2=94$, dengan $\mathrm{df}=94$ dan alpha 0,1 didapat $\mathrm{r}$ Tabel $=0,1689$. Bandingkan nilai correlated item- total correlation dengan hasil perhitungan $\mathrm{r}$ Tabel. Jika $\mathrm{R}_{\text {Hitung }}>\mathrm{R}_{\text {Tabel }}$ dan nilai positif maka butir atau pertanyaan atau indikator tersebut Valid [17], [18].

b. Uji Reliabilitas Untuk mengetahui tingkat ketepatan/tingkat presisi suatu ukuran atau alat pengukur karena syarat untuk kualifikasi suatu instrumen pengukur adalah konisten atau tidak berubah-ubah [18]. Karena instrument yang digunakan menggunakan jawaban berskala maka uji reliabilitas menggunakan Cronbach Alpha. Reliabilitas instrumen dilihat dari indeks reliabilitasnya, Jika indeks reliabilitas mendekati 1,00 maka instrument semakin reliabel. Sebaliknya jika indeks reliabilitas mendekati 0,00 maka instrumentnya tidak reliabel. Pengujian reliabilitas ini menggunakan alat bantu software SPSS 22 [19],[20].. 


\subsection{Analisa Data menggunakan Importance Performance Analysis (IPA)}

IPA mempunyai fungsi utama untuk menampilkan informasi berkaitan dengan atributatribut yang menurut pengguna Sistem informasi Akademik berada dalam tingat yang rendah [7],[21] . Dalam penelitian dapat dihitung tingkat kesesuaian setiap indikator variabel dimensi kualitas pelayanan berdasarkan hasil jumlah perhitungan rata - rata skor jasa yang diharapkan (ekspetasi) dengan jasa yang dirasakan ( presepsi ) oleh pengguna Sistem Informasi Akademik di Universitas Kadiri. Setelah diketahui tingkat kesesuaian dari masing-masing dimensi kualitas pelayanan maka dapat kita melakukan perhitungan untuk menentukan skor rata- ratanya untuk persepsi ekspetasi, kemudian dari hasil rata-ata persepsi dan ekspektasi didapatkan diagram kartesius yang terdapat sumbu $\mathrm{X}$ dan $\mathrm{Y}$ yaitu sumbu perpotongan $\mathrm{X}$ adalah hasil rata-rata skor jasa yang rasakan (kinerja/persepsi) sebesar 3,13 dan Y adalah rata-rata skor jasa yang diharapkan (ekspetasi) sebesar 3,59. Sehingga dari hasil tersebut dapat digambar diagram kartesius sebagai berikut :

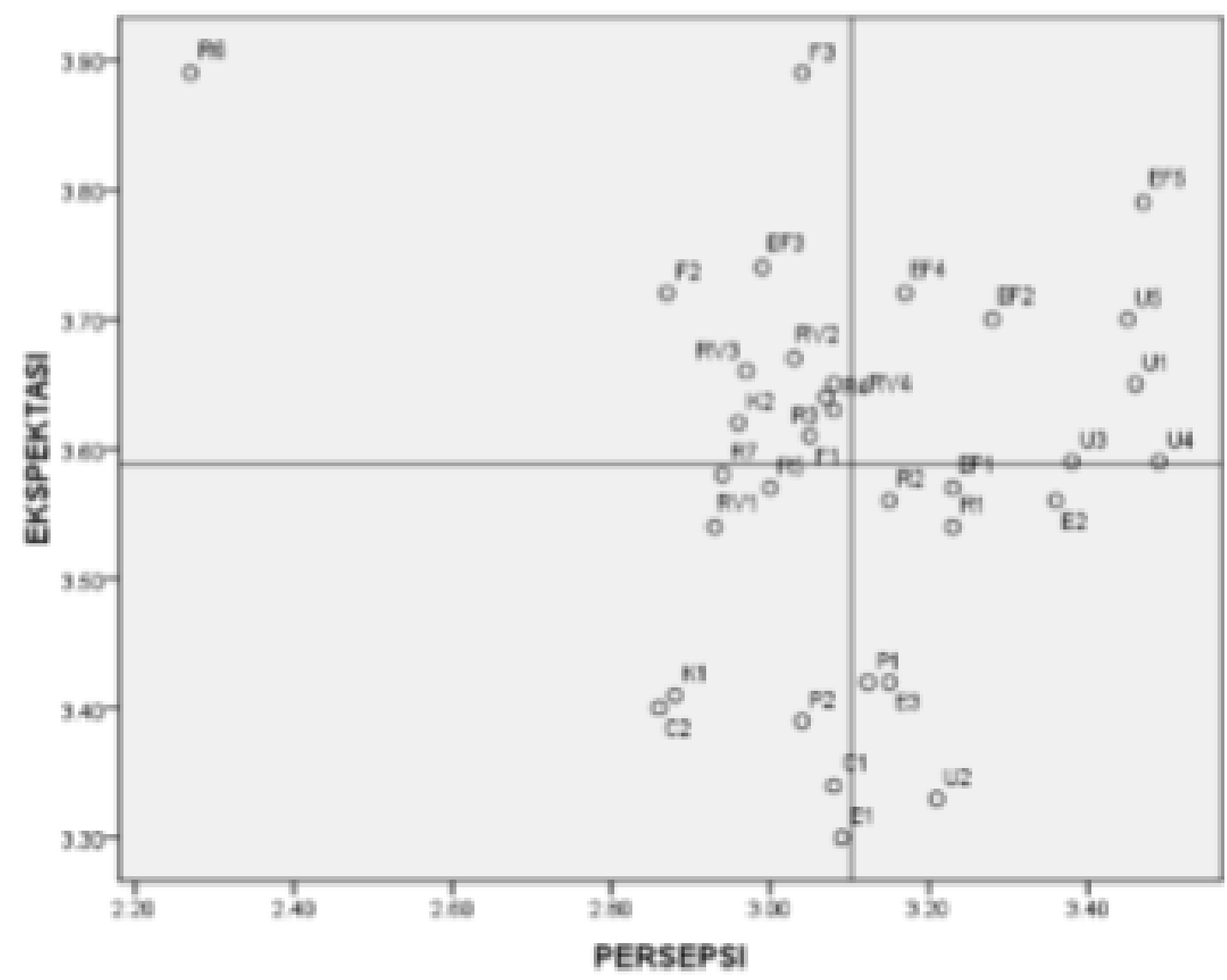

Gambar 1 Diagram Kartesius Dimensi Kepuasan Pengguna Sistem Informasi Akademik Mahasiswa Universitas Kadiri 
Atribut yang berada pada kuadran 1 dapat dilihar pada tabel dibawah ini :

Tabel 2 Atribut yang masuk pada Kuadran I

\begin{tabular}{|c|c|c|c|c|}
\hline No & Item & Atribut & $\begin{array}{l}\text { Rata - } \\
\text { rata } \\
\text { persepsi }\end{array}$ & $\begin{array}{l}\text { Rata }- \\
\text { rata } \\
\text { ekspetasi }\end{array}$ \\
\hline 1 & EF3 & $\begin{array}{l}\text { Informasi di situs } \\
\text { ini terorganisasi } \\
\text { dengan baik }\end{array}$ & 2,99 & 3,74 \\
\hline 2 & F1 & $\begin{array}{l}\text { Situs ini dengan } \\
\text { cepat memberikan } \\
\text { apa yang saya } \\
\text { inginkan }\end{array}$ & 3,05 & 3,61 \\
\hline 3 & $\mathrm{~F} 2$ & $\begin{array}{l}\text { Perubahan data } \\
\text { sesuai dengan } \\
\text { waktu kebutuhan }\end{array}$ & 2,87 & 3,72 \\
\hline 4 & F3 & $\begin{array}{l}\text { Informasi yang } \\
\text { tersedia sesuai } \\
\text { dengan fakta }\end{array}$ & 3,04 & 3,89 \\
\hline 5 & K2 & $\begin{array}{l}\text { Situs ini memberi } \\
\text { kompensasi untuk } \\
\text { masalah yang } \\
\text { diakibatkannya }\end{array}$ & 2,96 & 3,62 \\
\hline 6 & R3 & $\begin{array}{l}\text { Situs dapat dibuka } \\
\text { setiap kali diakses }\end{array}$ & 3,07 & 3,64 \\
\hline 7 & R4 & $\begin{array}{l}\text { Situs dapat dibuka } \\
\text { setiap kali diakses }\end{array}$ & 3,08 & 3,63 \\
\hline 8 & R6 & $\begin{array}{lr}\text { Semua form isian } \\
\text { didalam } & \text { situs } \\
\text { berfungsi dengan } \\
\text { baik }\end{array}$ & 3,27 & 3,89 \\
\hline 9 & RV2 & $\begin{array}{l}\text { Permintaan yang } \\
\text { diajukan } \\
\text { diperoses dengan } \\
\text { cepat }\end{array}$ & 3,03 & 3,89 \\
\hline 10 & RV3 & $\begin{array}{l}\text { Mekanisme } \\
\text { penanganan } \\
\text { masalah situs } \\
\text { berjalan dengan } \\
\text { cepat }\end{array}$ & 2,97 & 3,66 \\
\hline 11 & RV4 & $\begin{array}{lr}\text { Situs } & \text { ini } \\
\text { memberitahu saya } \\
\text { mengenai } & \text { apa } \\
\text { yang harus } \\
\text { dilakukan jika } \\
\text { informasi yang } \\
\text { saya butuhkan } \\
\text { tidak diproses }\end{array}$ & 3,08 & 3,65 \\
\hline
\end{tabular}




\section{Kesimpulan}

Berdasarkan hasil pengumpulan, pengolahan dan analisa data yang telah dilakukan pada bab sebelumnya dapat disimpulkan bahwa : 
1. Kepuasan pengguna Sistem Informasi Akademik atau SIAKAD mahasiswa masih rendah, dikarenakan rata-rata persepsi lebih rendah dibanding rata-rata ekspektasi pengguna yaitu dengan rata-rata persepsi sebesar 3,13 dan rata-rata ekspektasi sebesar 3,59.

2. Berikut atribut-atribut E-Servqual yang paling rendah yaitu atribut-atribut yang menempati diagram kartesius pada kuadran 1 yang berarti atribut-atribut ini diharapkan atau dianggap penting bagi pengguna tetapi pada kenyataannya dinilai masih kurang antara lain :

a. Dimensi Fullfilment yaitu pengguna menginginkan sistem informasi akademik atau SIAKAD memberikan kebutuhan pengguna lebih cepat, perubahan data pada SIAKAD tidak sesuai dengan waktu kebutuhan pengguna dan pengguna ingin informasi yang tersedia pada SIAKAD sesuai dengan fakta.

b. Dimensi Reliability yaitu diharapkan SIAKAD dapat diakses kapan saja oleh pengguna dan pengguna berharap form-form isian yang terdapat dalam SIAKAD dapat berfungsi dengan baik.

c. Dimensi Responsiveness yaitu SIAKAD tidak memproses permintaan yang diajukan pengguna dengan cepat oleh karena itu pengguna menginginkan kecepatan pemrosesan data pada SIAKAD lebih ditingkatkan, pengguna menginginkan mekanisme penanganan masalah pada SIAKAD berjalan lebih cepat dan SIAKAD tidak memberikan informasi kepada pengguna jika SIAKAD tidak memroses permintaan pengguna.

d. Dimensi Efficiency yaitu informasi di SIAKAD tidak terorganisasi dengan baik dan pengguna berharap bahwa situs tertata dengan baik dan lebih optimal dalam memenuhi fungsinya.

e. Dimensi Compentation yaitu SIAKAD tidak memberikan kompensasi kepada pengguna ketika SIAKAD sedang terjadi masalah.

Berdasarkan kesimpulan yang di peroleh dari hasil penelitian ini, saran yang direkomendasikan pada penelitian ini ialah sebagai berikut :

1. Bagi peneliti selanjutnya dapat menjadi sumber referensi penelitian, dengan konsep dan metode serta hasil analisis yang nantinya dapat lebih dikembangkan dan disempurnakan terlebih mengenai pengaruh atribut terhadap kepuasan pengguna sistem informasi akademik mahasiswa.

2. Bagi Universitas diharapkan dapat lebih meningkatkan kualitas pelayanan sistem informasi akademik dalam hal fulfilment, reliability, responsiveness, eficiency dan compentation. Selalu mengupdate bahan dari website sebelum dipublikasikan dan dibuktikan keakuratannya, universitas diharapkan bekerjasama dengan konsultan IT yang telah berpengalaman dalam mengembangkan sistem informasi manajemen kampus, dan kapasistas server harus disesuaikan dengan jumlah user atau mahasiswa di kampus agar situs tidak error ketika diakses oleh pengguna.

\section{Daftar Pustaka}

[1] H. Mardhiana, R. Amelia, Z. Ully, and A. Anfazul, "Kerangka Konseptual Kepuasan Pelanggan terhadap Jasa Transportasi Online Go Ride menggunakan Service Quality," pp. 1-8, 2015.

[2] E. Cristobal-Fransi, F. Hernández-Soriano, B. Ferrer-Rosell, and N. Daries, "Exploring service quality among online sharing economy platforms from an online media perspective," Sustain., vol. 11, no. 13, 2019.

[3] M. E. D. Putra, "EFEKTIFITAS E-SERVQUAL UNTUK MENCIPTAKAN KEPUASAN DAN LOYALITAS PENGGUNA E-BANKING Mario Eka Darma Putra Fakultas Ekonomi dan Bisnis Universitas Ma Chung."

[4] S. Riza and Sutopo, "Analisis Pengaruh E-Service Quality , Kualitas Informasi Dan Persepsi Kemudahan Terhadap E- Intervening,” Diponegoro J. Manag., vol. 6, pp. 1-13, 2017.

[5] T. T. Haria and M. R. Mulyandi, "Pengaruh E-Service Quality terhadap E-Satisfaction pada Pengguna Aplikasi Mobile,” vol. 6, no. 1, pp. 135-140, 2019.

[6] A. S. Alnaser, M. Khalid, Almsafir, and H. o. Alshoura, "E-SERVICE QUALITY : CONCEPTUAL APPROACH," Des. Sci. Renaiss., 2017. 
[7] H. Jonathan, "Analisis Pengaruh E-Service Quality terhadap Customer Satisfaction yang Berdampak pada Customer Loyalty PT Bayu Buana Travel Tbk," The Winners, vol. 14, no. 2, p. 104, 2013.

[8] O. D. Rareş, "Measuring Perceived Service Quality Offline vs. Online: A New PeSQ Conceptual Model," Procedia Econ. Financ., vol. 15, no. 14, pp. 538-551, 2014.

[9] F. Cahen and F. M. Borini, "International Digital Competence," J. Int. Manag., vol. 26, no. 1, p. $100691,2020$.

[10] R. Fauziyah, Y. Rohayati, and B. H. Sagita, "Integrating e-servqual and kano model to improve adorable projects website service quality," J. Sist. dan Manaj. Ind., vol. 3, no. 2, p. 98, 2019.

[11] A. Maksum, "Pengumpulan data," J. Metod. pengumpulan data, 2012.

[12] Sugiyono, “Teknik Pengumpulan Data," Metod. Penelit. Kuantitatif, Kualitatif dan R\&D, p. $137,2014$.

[13] M. P. Dr. Whidmurni, "Penelitian Kuantitatif," Pemaparan Metod. Kuantitatif, 2017.

[14] Ali Maksum, "Data, Teknik Pengumpulan Data dan Instrumen Penelitian," J. Cakrawala Kependidikan, no. agustus, p. 107, 2012.

[15] A. Hidayat, "Cara Hitung Rumus Slovin Besar Sampel,” Statistikian, 2017. .

[16] Sugiyono, "Metode Penelitian Kuantitatif, Kualitatif dan R\&D,” Tek. Ind., vol. 1, 2011.

[17] D. Panentu and M. Irfan, "Uji Validitas Dan Reliabilitas Butir Pemeriksaan Dengan Moteral Cognitive Assessment Versi Indonesia ( MoCA- INA) Pada Insan Pasca Stroke Fase Recovery," J. Fisioter., 2013.

[18] O. C. Salim, N. I. Sudharma, R. K. Kusumaratna, and A. Hidayat, "Validitas dan reliabilitas World Health Organization Quality of Life-BREF untuk mengukur kualitas hidup lanjut usia," Universa Med., 2016.

[19] A. Field, Discovering statistics using IBM SPSS statistics. 2013.

[20] P. D, “Belajar Cepat Olah Data Statistik dengan SPSS,” in Uji Validitas dan Reliabilitas, 2012.

[21] Y. Jeong, I. Chae, I. Yang, H. Kim, and H. Lee, "Analysis of Relative Importance of Key Performance Indicators for Center for Child-Care Foodservice Management through Analytic Hierarchy Process (AHP)," vol. 18, no. 2, pp. 154-164, 2013. 